\title{
Hybrid palliation for critical systemic outflow obstruction: Neither rapid stage 1 Norwood nor comprehensive stage 2 mitigate consequences of early risk factors
}

\author{
Ryan R. Davies, MD, ${ }^{\mathrm{a}, \mathrm{b}}$ Wolfgang Radtke, MD, ${ }^{\mathrm{a}, \mathrm{b}}$ Majeed A. Bhat, MD, ${ }^{\mathrm{a}, \mathrm{b}}$ Jeanne M. Baffa, MD, \\ Edward Woodford, PA-C, ${ }^{\mathrm{a}}$ and Christian Pizarro, $\mathrm{MD}^{\mathrm{a}, \mathrm{b}}$
}

\begin{abstract}
Objective: Hybrid palliation with branch pulmonary artery banding (bPAB) has become increasingly common in the early management of patients with critical left ventricular outflow obstruction. Optimal subsequent surgical palliation remains undefined.
\end{abstract}

\begin{abstract}
Methods: We retrospectively reviewed patients undergoing initial bPAB for single ventricle physiology with systemic outflow obstruction $(2001-2013, \mathrm{n}=37)$. Patients were stratified by subsequent surgical palliation: stage 1 Norwood $(\operatorname{St} 1 \mathrm{~N}, \mathrm{n}=14)$, comprehensive stage $2($ CompSt $2, \mathrm{n}=11)$, and none $(\mathrm{n}=12)$.

Results: bPAB was performed at a median of 4 days and $2.7-\mathrm{kg}$, post-bPAB mortality was increased in patients with aortic atresia (odds ratio $[\mathrm{OR}]=3.8,95 \%$ confidence interval $[\mathrm{CI}]=0.9-15.8$ ) or birth weight $<2 \mathrm{~kg}$ $(\mathrm{OR}=13.8,95 \% \mathrm{CI}=1.4-136.4)$. Palliation strategy did not affect transplant-free survival through secondstage palliation (St1N: $71.4 \%$, CompSt2: 72.7\%, $P=.9$ ). Among CompSt2 patients, there was a trend toward poorer survival with aortic atresia $(0 \%$ vs $80 \%, P=.09)$; birth weight $<2.5 \mathrm{~kg}$ was associated with decreased survival $(0 \%$ vs $89.0 \%, P=.01)$. A trend toward lower survival with low birth weight was evident among St1N patients $(<2 \mathrm{~kg}, \mathrm{OR}=0.1,95 \% \mathrm{CI}=0.01-1.9, P=.09)$. CompSt2 mortality occurred on postoperative days 0 and 1. Mortality following St1N occurred at a median of 38.5 days (range $=23.5-104.5$ ). Among survivors of stage 2 palliation, Fontan completion was performed in the same number of patients in each group (St $1 \mathrm{~N}: 6 / 8$, $75 \%$, CompSt2: 6/8, 75\%).
\end{abstract}

Conclusions: Both St1N and CompSt2 are viable options for subsequent palliation following initial hybrid procedure. Transplant-free survival and eventual Fontan candidacy are similar between groups. Delaying surgical palliation with the CompSt2 did not mitigate the impact of early risk factors such as low birth weight and aortic atresia. (J Thorac Cardiovasc Surg 2015;149:182-93)

See related commentary on page 194 .

Over the past 2 decades, improvements in both operative technique and perioperative management have resulted in improved survival following the stage 1 Norwood (St1N) procedure. $^{1,2}$ Unfortunately, mortality remains high, and transplant-free survival at 1 year is only $60 \%$ to $70 \%{ }^{3}$ following the Norwood procedure. Multiple risk factors for poor outcomes have been identified, and these include the presence of aortic atresia, low birth weight, lower

From the Nemours Cardiac Center, ${ }^{\mathrm{a}}$ Nemours/A.I. duPont Hospital for Children, Wilmington, Del; and Thomas Jefferson University, ${ }^{\mathrm{b}}$ Philadelphia, Pa.

Disclosures: Wolfgang Radtke reports consulting fees from St. Jude Medical. The other authors have nothing to disclose with regard to commercial support.

Read at the 94th Annual Meeting of The American Association for Thoracic Surgery, Toronto, Ontario, Canada, April 26-30, 2014.

Received for publication April 14, 2014; revisions received Aug 21, 2014; accepted for publication Sept 7, 2014; available ahead of print Oct 11, 2014.

Address for reprints: Ryan R. Davies, MD, Nemours/A.I. duPont Hospital for Children, 1600 Rockland Rd, Wilmington, DE 19806 (E-mail: rdavies@ nemours.org). 0022-5223/\$36.00

Copyright (c) 2015 by The American Association for Thoracic Surgery

http://dx.doi.org/10.1016/j.jtcvs.2014.09.030 gestational age, and genetic syndromes. ${ }^{1-4}$ In addition, patients presenting in shock (often due to delayed diagnosis) have significantly poorer outcomes. ${ }^{1}$

Hybrid palliation with branch pulmonary banding (bPAB) has been advocated as one method of mitigating these risk factors by delaying a large operation until patients have moved out of the immediate neonatal period. ${ }^{5-10}$ Multiple palliation strategies may be used following placement of $\mathrm{bPAB}$, and there is currently no consensus as to the optimal strategy. ${ }^{5-10}$

Among the alternatives, an initial hybrid approach with bPAB and ductal stenting followed by later comprehensive stage 2 (CompSt2) represents the most radical departure from the traditional staged palliation for patients with single ventricle physiology and systemic outflow obstruction. However, to date, this strategy has not resulted in overall improvements in survival when compared to the traditional early St1N. ${ }^{5,11}$ Others have suggested that routine bPAB be used with prostaglandin $\mathrm{E}_{1}\left(\mathrm{PGE}_{1}\right)$ to maintain ductal patency until a traditional $\mathrm{St} 1 \mathrm{~N}$ is performed approximately 3 to 4 weeks later. ${ }^{7}$ Finally, as reported by our group, ${ }^{12}$ bPAB has also been used selectively in order to stabilize high-risk patients prior to either early stage 1 or heart transplantation. ${ }^{8,9,13}$ 


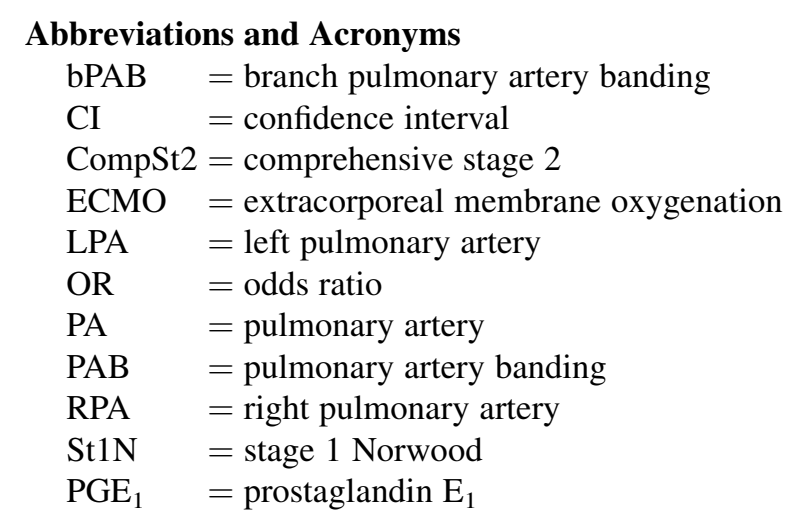

Management strategies are center-specific and little data exist to support one approach over another.

In order to assess outcomes following bPAB placement, we performed a retrospective review and analysis of patients following hybrid palliation who subsequently went through either an early modified $\mathrm{St} 1 \mathrm{~N}$ or a CompSt2 procedure. Predictors of overall survival, as well as survival within each palliation strategy, were assessed in order to determine whether certain patients would benefit from a particular strategy.

\section{METHODS}

\section{Data Source}

This is a retrospective study of all patients undergoing bilateral bPAB at a single institution (2001-2013). Data were collected from electronic medical record and institutional databases. This project was approved by the Nemours Institutional Review Board and need for consent was waived.

\section{Study Population, Inclusionary and Exclusionary Criteria}

All patients undergoing bPAB were included $(\mathrm{n}=37)$. Patients were stratified into 2 groups based on subsequent surgical palliation: St1N $(\mathrm{n}=14)$, CompSt2 $(\mathrm{n}=11)$. Outcomes following bPAB are shown for all patients $(\mathrm{n}=37)$; outcomes following subsequent staged palliation focus only on St1N and CompSt 2 patients. Patients who subsequently underwent a 2-ventricle repair or orthotopic heart transplant-without either St1N or CompSt2-were excluded.

\section{Operative Technique and Clinical Management Strategy}

Technical details of the hybrid procedure have been previously reported. ${ }^{14}$ In summary, bilateral PABs were placed without cardiopulmonary bypass and typically over a $2.5-\mathrm{mm}$ probe. Bands were adjusted to achieve systemic oxygen saturation in the $80 \%$ to $85 \%$ range with balanced circulation. Direct cannulation of the pulmonary artery was performed for ductal stenting. A lateral angiogram was performed to delineate ductal as well as arch anatomy in order to inform the choice of stent and the area of deployment.

Bilateral bPAB was performed prior to either ductal stenting or St $1 \mathrm{~N}$ in order to balance the pulmonary-to systemic flow ratio $(\mathrm{Qp} / \mathrm{Qs})$ and/or treat maldistribution of cardiac output associated with end-organ dysfunction. A hybrid approach was considered when contraindication for anticoagulation existed or for conditions associated with lower survival following the
Norwood procedure, including shock at the time of diagnosis, prematurity, low birth weight, chromosomal anomalies, as well as important medical issues requiring immediate intervention such as duodenal atresia or tracheoesophageal fistula.

Balloon atrial septostomy was not routinely performed before or at the time of bPAB and was performed only if the estimated mean gradient across the atrial septal defect was $>5 \mathrm{~mm} \mathrm{Hg}$ in association with a decrease in arterial oxygen saturation levels and changes in the chest radiograph consistent with increasing pulmonary vascular congestion. For purposes of analysis, a reverse coarctation was defined as a velocity of $>2.5 \mathrm{~m} / \mathrm{s}$ by Doppler echocardiography among patients with aortic atresia.

Modified St1N palliation was performed using deep hypothermic circulatory arrest; pulmonary blood flow was provided by either a right ventricle-pulmonary artery conduit or a modified Blalock-Taussig shunt. Superior cavopulmonary connections (SCPCs) consisted of a Hemi-Fontan or bidirectional Glenn. Choice of pulmonary blood flow at first-stage palliation, and the type of SCPC were both chosen at the surgeon's discretion.

The decision to proceed with an early St $1 \mathrm{~N}$ and the timing of the procedure were determined on an individual basis depending on individual risk factors. In the setting of modifiable risk factors (eg, shock, renal insufficiency, or low weight), we preferred to proceed with an early St1N following resolution of the risk factor or factors. Achievement of hemodynamic stability with resolution of shock (as assessed by lactate levels) and normalization of creatinine were primary considerations. In patients with either ventricular dysfunction or significant atrioventricular valve regurgitation, improvement in these parameters on echocardiography was also a factor. In premature infants and those with low birth weight, achievement of a weight above $2.5 \mathrm{~kg}$ was also desirable. No specific time period between $\mathrm{bPAB}$ placement and $\mathrm{St} 1 \mathrm{~N}$ was determined a priori as ideal. Among patients who underwent ductal stenting, the intention was for subsequent palliation to be a CompSt2 procedure, but patients who developed unbalanced circulations, atrioventricular valve regurgitation, ventricular dysfunction, evidence of retrograde flow acceleration ("reverse coarctation"), or a significant distal recoarctation were converted back to a standard palliation pathway through the use of an $\mathrm{St} 1 \mathrm{~N}$ procedure.

\section{Statistical Analysis}

Statistical analysis was performed using SAS 9.13 for AIX (SAS Inc, Cary, NC) and Prism 6.0 for Mac (GraphPad Software Inc, La Jolla, Calif). For comparisons of dichotomous variables with binary outcomes, $\chi^{2}$ analysis was performed; variables are reported as $\mathrm{n}(\%)$. Comparison between continuous variables was performed using Student $t$ tests. Continuous variables are reported as median (interquartile range) or mean \pm standard deviation. Multivariable logistic regression analysis was performed to assess predictors of binary outcomes (backward selection, $P<.2$ ); variables predictive in univariable modeling were included in the model.

Primary outcome was transplant-free survival through the second-stage palliation (defined as survival beyond 30 days following successful second-stage palliation). Secondary outcomes included operative mortality following surgical palliation (St1N or CompSt2), survival to Fontan procedure, midterm survival (starting at placement of bPAB), and hemodynamic and angiographic assessments of the pulmonary arteries. Reported bPAB diameter measurements are based on the dilator over which the band was placed. Subsequent pulmonary artery measurements represent the smallest diameter measured by angiography in the right or left branch PA proximal to any lobar branches.

\section{RESULTS}

\section{Baseline Demographics and Initial Clinical Pathway}

Baseline demographic for both groups of patients, as well as those not undergoing subsequent surgical single ventricle 
TABLE 1. Baseline clinical characteristics among patients undergoing bilateral pulmonary artery banding stratified by subsequent palliation

\begin{tabular}{|c|c|c|c|c|c|}
\hline Variable & Overall & St1N $(n=14)$ & $\operatorname{CompSt} 2(n=11)$ & None $(n=12)$ & $P$ value \\
\hline Gender (male) & $28 / 37(75.7 \%)$ & $11 / 14(78.6 \%)$ & $9 / 11(81.82 \%)$ & $8 / 12(66.7 \%)$ & 6 \\
\hline \multicolumn{6}{|l|}{ Birth history } \\
\hline Gestational age (wk), mean (range) & $37(36-39)$ & & & & \\
\hline Prematurity $(<37 \mathrm{wk})$ & $17 / 37(46.0 \%)$ & $6 / 14(42.9 \%)$ & $5 / 11(45.5 \%)$ & $6 / 12(50.0 \%)$ & .9 \\
\hline Birth weight $(\mathrm{kg})$, mean (range) & $2.6(2.2-3.1)$ & & & & \\
\hline Low birth weight $(<2 \mathrm{~kg})$ & $6 / 36(16.7 \%)$ & $3 / 14(21.4 \%)$ & $0 / 11(0.0 \%)$ & $3 / 11(27.3 \%)$ & .19 \\
\hline Low birth weight $(<2.5 \mathrm{~kg})$ & $15 / 36(41.7 \%)$ & $7 / 14(50.0 \%)$ & $2 / 11(18.2 \%)$ & $6 / 11(54.6 \%)$ & .09 \\
\hline \multicolumn{6}{|l|}{ Diagnosis } \\
\hline Hypoplastic left heart syndrome & & $9 / 14(64.3 \%)$ & $6 / 11(54.6 \%)$ & $11 / 12(91.7 \%)$ & .2 \\
\hline Critical AS & & & $3 / 11(27.3 \%)$ & & \\
\hline Interrupted aortic arch & $1 / 37(2.7 \%)$ & $1 / 14(7.1 \%)$ & $0 / 11(0.0 \%)$ & $0 / 12(0.0 \%)$ & .4 \\
\hline Unbalanced AVSD & $4 / 37(10.8 \%)$ & $2 / 14(14.3 \%)$ & $0 / 11(0.0 \%)$ & $2 / 12(16.7 \%)$ & .4 \\
\hline TGA & $2 / 37(5.4 \%)$ & $1 / 14(7.1 \%)$ & $1 / 11(9.1 \%)$ & $0 / 12(0.0 \%)$ & \\
\hline DORV & $2 / 37(5.4 \%)$ & $2 / 14(14.3 \%)$ & $0 / 11(0.0 \%)$ & $0 / 12(0.0 \%)$ & .2 \\
\hline MA & $15 / 37(40.5 \%)$ & $7 / 14(50.0 \%)$ & $1 / 11(9.1 \%)$ & $7 / 12(58.3 \%)$ & .04 \\
\hline AA & $18 / 37(48.7 \%)$ & $8 / 14(57.1 \%)$ & $1 / 11(9.1 \%)$ & $9 / 12(75.0 \%)$ & .005 \\
\hline AA/MA & $11 / 37(29.7 \%)$ & $6 / 14(42.9 \%)$ & $1 / 11(9.1 \%)$ & $5 / 12(41.7 \%)$ & .001 \\
\hline AA/MS & $4 / 37(10.8 \%)$ & $1 / 14(7.1 \%)$ & $0 / 11(0.0 \%)$ & $3 / 12(25.0 \%)$ & \\
\hline AS/MS & $10 / 37(27.0 \%)$ & $1 / 14(7.1 \%)$ & $8 / 11(72.7 \%)$ & $1(8.3 \%)$ & \\
\hline AS/MA & $2 / 37(5.4 \%)$ & $0 / 14(0.0 \%)$ & $0 / 11(0.0 \%)$ & $2 / 12(16.7 \%)$ & \\
\hline \multicolumn{6}{|l|}{ Clinical condition } \\
\hline Mechanical ventilation & $19 / 36(52.8 \%)$ & $7 / 14(50.0 \%)$ & $5 / 11(45.5 \%)$ & $7 / 11(63.6 \%)$ & .7 \\
\hline ECMO/ECLS & $1 / 37(2.7 \%)$ & $0 / 0(0.0 \%)$ & $0 / 0(0.0 \%)$ & $1 / 12(8.3 \%)$ & .3 \\
\hline AVV regurgitation $>$ moderate & $7 / 35(27.3 \%)$ & $1 / 14(7.1 \%)$ & $3 / 10(30.0 \%)$ & $3 / 11(27.3 \%)$ & .3 \\
\hline Ventricular dysfunction $>$ moderate & $11 / 34(32.4 \%)$ & $2 / 14(14.3 \%)$ & $6 / 10(60.0 \%)$ & $3 / 10(30.0 \%)$ & .06 \\
\hline \multicolumn{6}{|l|}{ Combinations of risk factors } \\
\hline Birth weight $<2 \mathrm{~kg}+$ aortic atresia & $3 / 37(8.1 \%)$ & $1 / 14(7.1 \%)$ & $0 / 11(0.0 \%)$ & $2 / 12(16.7 \%)$ & .3 \\
\hline Prematurity + aortic atresia & $7 / 37(18.9 \%)$ & $2 / 14(14.3 \%)$ & $0 / 11(0.0 \%)$ & $5 / 12(41.7 \%)$ & .03 \\
\hline Apgar score (1-min/5-min), mean (range) & $8(5-9) / 9(8-9)$ & & & & \\
\hline Apgar score $<7$ & $15 / 37(40.5 \%)$ & $3 / 11(21.4 \%)$ & $6 / 11(54.6 \%)$ & $6 / 12(50.0 \%)$ & \\
\hline Genetic syndrome & $3 / 33(9.1 \%)$ & $2 / 13(15.4 \%)$ & $0 / 9(0.0 \%)$ & $1 / 11(9.1 \%)$ & .5 \\
\hline Noncardiac congenital anomaly & $25 / 34(73.5 \%)$ & $12 / 13(92.3 \%)$ & $5 / 10(50.0 \%)$ & $8 / 11(72.7 \%)$ & .07 \\
\hline
\end{tabular}

StIN, Stage 1 Norwood; CompSt2, comprehensive stage 2; $A V S D$, atrioventricular septal defect; $T G A$, transposition of the great arteries; $D O R V$, double-outlet right ventricle; $A A$, aortic atresia; $M A$, mitral atresia; $M S$, mitral stenosis; $A S$, aortic stenosis; $E C M O$, extracorporeal membrane oxygenation; $E C L S$, extracorporeal life support; $A V V$, atrioventricular valve.

palliation, is shown in Table 1. The clinical pathway followed by all patients undergoing bPAB placement is shown in Figure 1 and Table 2. Placement of bPAB was performed at a median of 4 days (range $=3-8$ ) of life and at a weight of $2.7 \mathrm{~kg}$ (range $=2.2-3.1)$. Banded PA diameters were similar in both groups (left pulmonary artery [LPA], St1N: $2.5 \pm 0.3 \mathrm{~mm}$, CompSt2: $2.5 \pm 0.2 \mathrm{~mm} ; P=.6$ ) (right pulmonary artery [RPA], St1N: $2.5 \pm 0.3 \mathrm{~mm}$, CompSt2: $2.5 \pm 0.2 \mathrm{~mm} ; P=.9)$.

\section{Early Outcomes Following Pulmonary Artery Banding}

Low birth weight $(<2 \mathrm{~kg})$ was the predominant predictor of operative mortality following bPAB placement $(83.3 \%$ vs birth weight $>2 \mathrm{~kg}=26.7 \%$, OR $=13.8,95 \%$ $\mathrm{CI}=1.5-136.4, P=.0008)$ for the entire cohort. Moreover, none of the patients with a combination of aortic atresia and low birth weight survived to discharge $(3 / 3, P=.01)$. Similarly, very high mortality was observed among premature neonates $(<37$ weeks gestation) with aortic atresia $(5 / 7$, $71.4 \%, \mathrm{OR}=6.9,95 \% \mathrm{CI}=1.1-42.8)$. Other factors, including ventricular dysfunction, atrioventricular valve regurgitation, and need for mechanical ventilation, were not significant predictors of operative mortality during bPAB placement.

Three patients died following branch PA banding while maintained on $\mathrm{PEG}_{1}$ without subsequent surgical palliation: 2 of these patients had birth weights $<1 \mathrm{~kg}$ ( 1 with a restrictive atrial septum), the third had a restrictive atrial septum and both aortic and mitral insufficiency.

Patients in the CompSt2 group were more likely to be discharged to home prior to their subsequent palliation $(10 / 11,90.0 \%$, vs $2 / 14,14.3 \% ; P=.0001)$.

\section{Outcome Among Patients Undergoing Ductal Stenting}

Simultaneous stenting of the ductus arteriosus was performed in 12 patients (32.4\%; Figure 1$)$. The remaining 


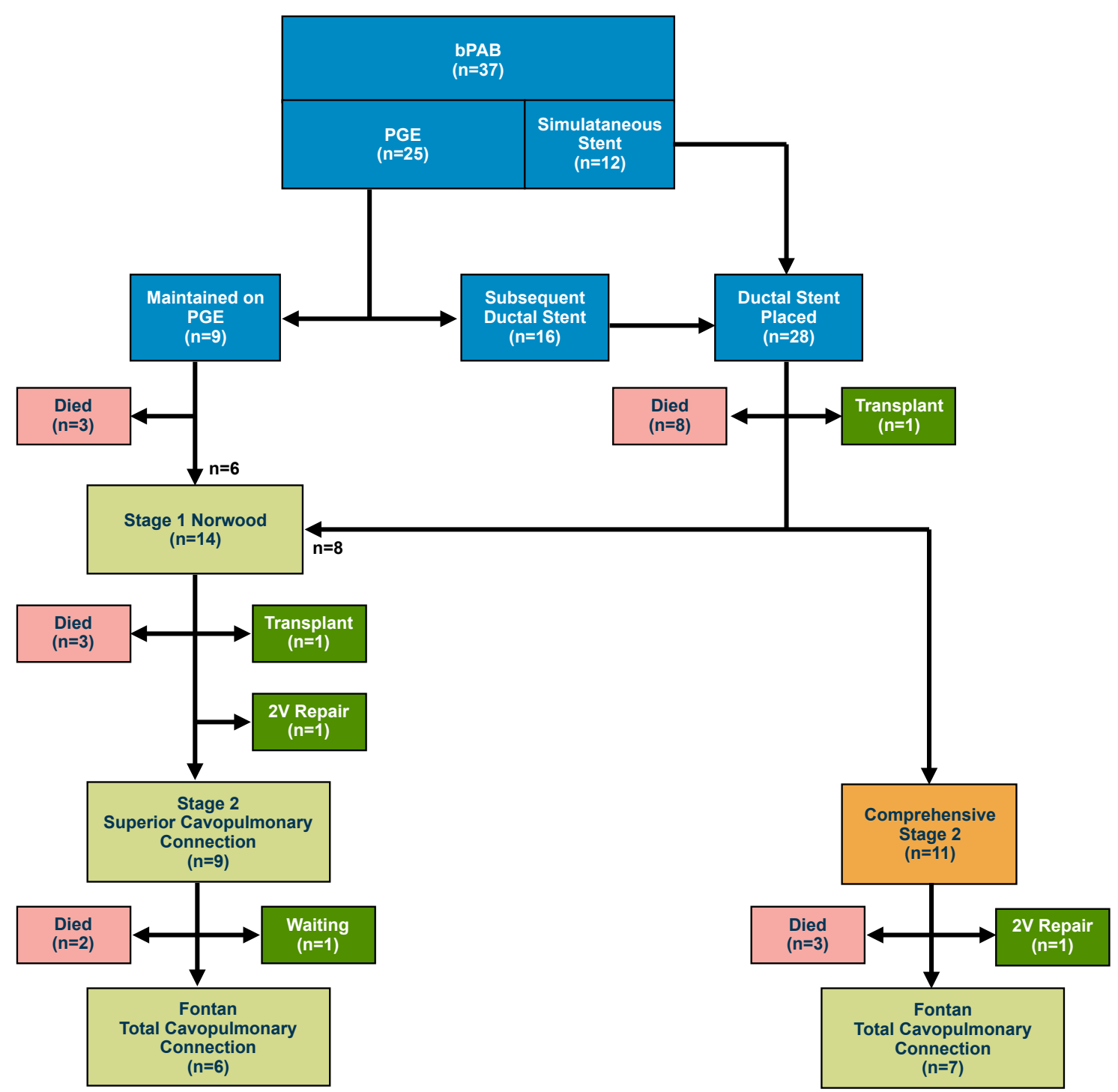

FIGURE 1. Flowchart illustrating procedural pathway and outcomes at each stage for patients undergoing branch pulmonary artery banding. $b P A B$, Branch pulmonary artery banding; $P G E$, prostaglandin E; $2 V, 2$-ventricle.

patients were maintained on $\mathrm{PGE}_{1}$ to maintain ductal patency. Following clinical stabilization, ductal stenting was performed in 16 additional patients $(43.2 \%)$, more commonly in the management pathway toward CompSt2 $(100.0 \%)$, compared to those undergoing St1N $(57 \%)$ or no further palliation $(75.0 \%, P=.05$; Figure 1$)$. Median interval from $\mathrm{bPAB}$ to ductal stent among patients not having simultaneous stenting was 6.5 days (interquartile range $=4-11.5$ days).

Two patients in the CompSt2 pathway required a reintervention on the ductal stent prior to subsequent palliation (vs 0 in the St $1 \mathrm{~N}$ group, $P=.2$ ). Among the 8 patients who underwent early St $1 \mathrm{~N}$ following a complete hybrid palliation (bPAB and ductal stent placement), the indications for proceeding to St1N rather than wait for a compSt 2 procedure were as follows: progressive hypoxia $(\mathrm{n}=2)$, resolution of early contraindication to cardiopulmonary bypass $(\mathrm{n}=1)$, increased flow acceleration through ductal stent or recoarctation $(n=4)$, and excessive pulmonary blood flow $(\mathrm{n}=1)$. In most cases with ductal recoarctation, the increased pressure load also resulted in increases in atrioventricular valve regurgitation. In these cases, our preference was to perform a surgical palliation rather than multiple additional catheter-based or hybrid interventions. Four patients with aortic atresia developed mild retrograde arch obstruction (peak velocity $>2 \mathrm{~m} / \mathrm{s}$ ), and 1 of these patients had a retrograde coarctation $(>3$ $\mathrm{m} / \mathrm{s}$ ). Only the patient with a velocity $>3 \mathrm{~m} / \mathrm{s}$ demonstrated regional ventricular dysfunction, although the electrocardiogram did not have signs of ischemia; this patient received a transplant 3 weeks following demonstration of the retrograde obstruction. 


\begin{tabular}{|c|c|c|c|c|c|c|c|c|c|c|}
\hline ID & Diagnosis & $\begin{array}{c}\text { Gestational } \\
\text { age (wk) }\end{array}$ & $\begin{array}{l}\text { Birth } \\
\text { weight } \\
\text { (kg) }\end{array}$ & $\begin{array}{l}\text { Age at } \\
\text { PAB (d) }\end{array}$ & $\begin{array}{c}\text { Ductal stent } \\
\text { or PGE (days } \\
\text { since PAB) }\end{array}$ & $\begin{array}{c}\text { Duration } \\
\text { of PAB (d) }\end{array}$ & $\begin{array}{c}\text { Surgical } \\
\text { palliation (age, d) }\end{array}$ & $\begin{array}{c}\text { Death/ } \\
\text { Transplant } \\
\text { through } \\
\text { stage 2 } \\
\text { (age, d) }\end{array}$ & $\begin{array}{c}\text { Reverse } \\
\text { coarctation? }\end{array}$ & Outcome \\
\hline 1 & HLHS (AA, MA) & 40 & Unknown & 1 & Stent (11) & & & Yes (127) & No & \\
\hline 2 & HLHS (AS, MS) & 40 & 3.7 & 2 & Stent $(0)$ & 99 & CompSt2 (101) & & & \\
\hline 3 & HLHS (AS, MS) & 40 & 2.76 & 1 & Stent $(0)$ & 120 & CompSt2 (121) & & & \\
\hline 4 & HLHS (AS, MS) & 41 & 3.29 & 9 & Stent $(0)$ & 155 & CompSt2 (164) & & & \\
\hline 5 & $\begin{array}{l}\text { TGA }(\mathrm{S}, \mathrm{L}, \mathrm{L}) \text { with } \\
\text { aortic stenosis }\end{array}$ & 35 & 2.15 & 8 & Stent $(0)$ & 168 & CompSt2 (176) & Yes (176) & & Withdrawal of ECMO support \\
\hline 6 & AVSD (AA, MS) & 36 & 2.72 & 10 & Stent $(0)$ & 49 & St1N (59) & & No & Sepsis, MSOF, late death (248 d) \\
\hline 7 & $\begin{array}{r}\text { HLHS }(\mathrm{AA}, \mathrm{MS}), \\
\text { restrictive ASD }\end{array}$ & 30 & 0.92 & 32 & PGE1 & 1 & & Yes (33) & No & $\begin{array}{l}\text { Progressive restriction of } \\
\text { atrial septum, atrial septectomy, } \\
\text { ECMO with GI bleeding }\end{array}$ \\
\hline 8 & HLHS (AS, MS) & 39 & 3.19 & 3 & Stent (4) & 115 & CompSt2 (118) & & & \\
\hline 9 & HLHS (AS, MS) & 36 & 2.6 & 1 & Stent (6) & 97 & $\begin{array}{l}\text { CompSt2 (98), } \\
\text { take-down (98) }\end{array}$ & & & $\begin{array}{l}\text { Traumatic subarachnoid } \\
\text { hemorrhage, brain death }(208 \mathrm{~d})\end{array}$ \\
\hline 10 & HLHS (AA, MA) & 38 & 2.5 & 2 & Stent (2) & 120 & $\begin{array}{l}\text { CompSt2 (122), } \\
\text { take-down (122) }\end{array}$ & Yes (123) & No & MSOF \\
\hline 11 & HLHS (AS, MA) & 37 & 2.2 & 5 & Stent (8) & 67 & & Yes (72) & & Acute heart failure at home \\
\hline 12 & AVSD (AA) & 39 & 3.2 & 54 & Stent $(0)$ & 76 & & Yes (130) & No & Unknown \\
\hline 13 & $\begin{array}{r}\text { HLHS }(\mathrm{AA}, \mathrm{MS}), \\
\text { restrictive ASD }\end{array}$ & 34 & 2.3 & 1 & Stent (7) & 28 & St1N (29) & & No & \\
\hline 14 & HLHS (AA, MS) & 39 & 2.17 & 5 & Stent $(0)$ & 87 & & Yes (92) & No & Sepsis, renal failure \\
\hline 15 & HLHS (AA, MA) & 29 & 1.42 & 17 & Stent $(0)$ & 2 & & Yes (19) & No & $\begin{array}{l}\text { Circulatory collapse, withdrawal } \\
\text { of ECMO }\end{array}$ \\
\hline 16 & $\begin{array}{l}\text { Critical AS, } \\
\text { restrictive ASD }\end{array}$ & 39 & 2.86 & 28 & Stent $(0)$ & 103 & CompSt2 (131) & & & \\
\hline 17 & Critical AS & 38 & 2.8 & 6 & Stent $(0)$ & 144 & CompSt2 (150) & & & \\
\hline 18 & HLHS (AA, MA) & 37 & 3.6 & 4 & Stent (4) & 23 & St1N (27) & & No & \\
\hline 19 & HLHS (AA, MA) & 36 & 2.9 & 8 & Stent (15) & 77 & & Yes $(85)$ & No & Bradycardia, hypoventilation \\
\hline 20 & $\begin{array}{r}\text { HLHS (AS, MA), } \\
\text { restrictive ASD }\end{array}$ & 32 & 0.87 & 30 & PGE1 & & & Yes (43) & & $\begin{array}{l}\text { Intractable ventricular } \\
\text { arrhythmias, ? digoxin toxicity }\end{array}$ \\
\hline 21 & HLHS (AA, MA) & 39 & 3.2 & 3 & Stent (5) & 216 & & Txpl (216) & Yes $(3.1 \mathrm{~m} / \mathrm{s})$ & Transplant (216 d) \\
\hline 22 & $\begin{array}{l}\text { TGA }(S, D, D) \\
\text { tricuspid atresia, } \\
\text { critical outflow } \\
\text { obstruction }\end{array}$ & 34 & 1.8 & 3 & Stent (4) & 93 & St1N (96) & & & \\
\hline 23 & AS, MA & 37 & 1.7 & 8 & Stent (3) & 84 & St1N (92) & Yes (113) & & Sepsis, MSOF \\
\hline 24 & HLHS (AA, MA) & 38 & 2.59 & 4 & & 13 & St1N (17) & & No & \\
\hline 25 & HLHS (AS, MS) & 36 & 2.6 & 3 & Stent $(0)$ & 151 & CompSt2 (154) & & & \\
\hline 26 & HLHS (AA, MS) & 38 & 2.2 & 10 & Stent $(0)$ & 88 & & Yes (98) & No & Cardiac arrest \\
\hline 27 & DORV (AS, MA) & 39 & 3.14 & 4 & PGE1 & 4 & St1N (8) & Txpl (168) & & Acute circulatory collapse (778 d) \\
\hline 28 & HLHS (AS, MS) & 39 & 3.5 & 4 & PGE1 & 18 & & Yes (22) & & $\begin{array}{l}\text { Restrictive ASD, mitral } \\
\text { regurgitation, on ECMO from } \\
\text { banding, MSOF }\end{array}$ \\
\hline 29 & $\begin{array}{l}\text { Critical AS, } \\
\text { restrictive ASD }\end{array}$ & 39 & 3.1 & 3 & Stent (8) & 172 & CompSt2 (175) & & & \\
\hline 30 & AVSD (AS, MS) & 39 & 2.4 & 5 & Stent (13) & 98 & St1N (103) & & & MSOF, late death (259 d) \\
\hline 31 & HLHS (AS, MS) & 35 & 2.8 & 0 & PGE1 & 13 & St1N (13) & & & \\
\hline 32 & $\begin{array}{r}\text { HLHS }(\mathrm{AA}, \mathrm{MA}), \\
\text { restrictive ASD }\end{array}$ & 37 & 3.1 & 10 & Stent $(0)$ & 101 & St1N (111) & Yes (162) & No & $\begin{array}{l}\text { RV dysfunction, ECMO } \\
\text { complicated by } \\
\text { cerebral hemorrhage }\end{array}$ \\
\hline 33 & IAA (type B) & 37 & 2.5 & 4 & PGE1 & 10 & St1N (14) & & & \\
\hline 34 & HLHS (AS, MS) & 37 & 2.4 & 8 & Stent $(0)$ & 18 & St1N (26) & & & \\
\hline 35 & HLHS (AA, MA) & 32 & 1.7 & 5 & PGE1 & 27 & St1N (32) & Yes (58) & No & Subdural hemorrhage on ECMO \\
\hline 36 & HLHS (AA, MA) & 39 & 3.5 & 3 & & 11 & St1N (14) & & No & \\
\hline 37 & AVSD (AA, LAVVA) & 35 & 2.6 & 4 & Stent (13) & & & Yes (100) & No & $\begin{array}{l}\text { Respiratory failure, withdrawal of } \\
\text { support }\end{array}$ \\
\hline
\end{tabular}

$\overline{I D}$, Patient identification number; $P A B$, pulmonary artery banding; $P G E$, prostaglandin E; $H L H S$, hypoplastic left heart syndrome; $A A$, aortic atresia; $M A$, mitral atresia; $A S$, aortic stenosis; $M S$, mitral stenosis; CompSt2, comprehensive stage 2; TGA (S,L,L), transposition of the great arteries (S,L,L); ECMO, extracorporeal membrane oxygenation; $A V S D$, atrioventricular septal defect; St $1 N$, stage 1 Norwood; $M S O F$, multiple system organ failure; $A S D$, atrial septal defect; $P G E 1$, prostaglandin $\mathrm{E}_{1} ; G I$, gastrointestinal; TGA (S,D,D), transposition of the great arteries (S,D,D); DORV, double-outlet right ventricle; Txpl, transplant; $R V$, right ventricular; IAA, interrupted aortic arch; $L A V V A$, left atrioventricular valve atresia. 


\section{Early St1N}

Median age at St1N was 28 (range $=14-92)$ days and median weight was 3.0 (range $=2.7-3.9$ ) $\mathrm{kg}$. Operative mortality following St $1 \mathrm{~N}$ procedure was $28.6 \%$. Mortality was not affected by the presence of a ductal stent (stent: $37.5 \%$, PGE: $16.7 \%, P=.4$ ). Postoperative mortality following St1N $(n=4)$ occurred late $($ median $=38.5$ days, range $=23.5-104.5$ ). Deaths in this group were more often related to underlying comorbidities and late complications including atrioventricular valve regurgitation, diastolic myocardial dysfunction, sepsis, and intracerebral hemorrhage late following extracorporeal membrane oxygenation (ECMO) support. Patients surviving to discharge following St1N had a shorter duration of bPAB than those who died $(26.2 \pm 26.7$ vs $77.5 \pm 34.5$ days, $P=.01$ ). Postoperative ECMO was required in 4 patients following St1N $(28.6 \%)$. The use of ECMO was related to hypoxia in 1 patient and to low cardiac output in 3 . Two of $4(50 \%)$ of patients were successfully decannulated from ECMO, but the mortality rate among patients requiring postoperative ECMO was high $(75.0 \%)$.

\section{Second-Stage Palliation}

SCPC after St1N. Nine of the 14 patients in the St1N underwent second-stage palliation $(64.3 \%)$. Operative mortality following the SCPC in St1N patients was 1 of 9 $(11.1 \%)$.

Overall transplant-free survival through the second-stage procedure was $71.6 \%$. Aortic atresia was not a significant predictor of transplant-free survival through stage 2 $(63.5 \%$ vs $83.3 \%, \mathrm{OR}=0.3,95 \% \mathrm{CI}=0.3-4.4)$; there was a trend toward worse survival among patients with birth weight $<2 \mathrm{~kg}(\mathrm{OR}=0.1,95 \% \mathrm{CI}=0.01-1.9, P=.09)$. The presence of mitral atresia did predict decreased survival $(42.9 \%$ vs $100.0 \%, P=.018)$. The 8 patients who had an St1N following ductal stenting had a transplant-free survival $(75 \%)$ similar to those who were maintained on PGE1 $(66.7 \%, P=.7)$. Weight-for-age percentile and the change in weight-for-age percentile following bPAB were not predictive of transplant-free survival.

CompSt2. Operative mortality following CompSt2 was $18.2 \%(2 / 11)$. Postoperative deaths $(n=2)$ following CompSt 2 occurred early following the procedure, on postoperative days 0 and 1 . In both cases, the patients developed superior vena caval syndrome following SCPC. Despite institution of ECMO and enlargement of the superior cavopulmonary pathway in one patient and take-down to a modified Blalock-Taussig shunt in the other, neither patient could be saved. In addition to the patient who died, 1 other patient required a take-down of the SCPC following CompSt2. Patients requiring take-down of CompSt 2 had asymmetric bPAB placement (compared to none in the successful group, $P=.07)$. One patient had a $2.0-\mathrm{mm}$ right $\mathrm{PAB}$ and a $2.5-\mathrm{mm}$ left $\mathrm{PAB}$, whereas the other had a $2.5-\mathrm{mm}$ right $\mathrm{PAB}$ and a $3.0-\mathrm{mm}$ left $\mathrm{PAB}$. Preoperative angiographic and hemodynamic variables were not significantly different between these patients and those who had a successful stage 2 procedure. There was a trend toward shorter duration of $\mathrm{PAB}$ palliation (108.5 vs 136.3 days, $P=.2$ ) and younger age at CompSt2 (3.7 vs 4.8 months, $P=.1$ ) among the patients who did not tolerate the SCPC.

Following St2Comp palliation, mortality was higher in patients with aortic atresia $(100 \%$ vs $10 \%, P=.03)$, as well as in patients with birth weights $<2.5 \mathrm{~kg}(100 \%$ vs $0 \%, P=.0009$ ) (no patients under $2.0 \mathrm{~kg}$ underwent CompSt2 procedure). The duration for which the bPABs were in place did not affect mortality following CompSt2 procedure (survivors: $128.4 \pm 27.6$ days, nonsurvivors: $144.0 \pm 33.9$ days; $P=.5$ ).

Transplant-free survival through second-stage palliation was $72.7 \%(8 / 11)$. There was a trend toward poorer transplant-free survival among patients with aortic atresia $(0 \%$ vs $80.0 \%, P=.09)$. Patients with birth weights $<2.5$ $\mathrm{kg}$ had decreased survival $(0 \%$ vs $89.0 \%, P=.01)$. Weight-for-age percentile and the change in weight-forage percentile following $\mathrm{BPAB}$ were not predictive of transplant-free survival in CompSt2 patients.

Comparison of second-stage palliation (St1N vs CompSt2). CompSt2 occurred at earlier ages than SCPC in the St1N group (4.4 vs 6.3 months, $P=.004$ ). Weight-for-age percentiles were lower at the creation of the SCPC in the St1N group $(2.1 \% \pm 2.3 \%$ vs CompSt 2 : $11.1 \% \pm 10.9 \%, P=.025)$. There was no difference between groups in the mean change in weight-for-age percentiles between PAB placement and SCPC. Patients with birthweight $<2.5 \mathrm{~kg}$ reached second-stage palliation at a mean weight-for-age percentile of $3.6 \%$ (vs $8.5 \%$ among normal-birth-weight patients, $P=.3$ ); this represented a change in weight-for-age percentile of only $0.6 \%$ (vs $-17.0 \%$ among normal-birth-weight patients, $P=.1)$ Among patients with low birth weight $(<2.5 \mathrm{~kg})$, there was no difference between the change in weight-forage percentiles between St1N and CompSt 2 patients.

Transplant-free survival through the second stage did not differ between groups (St1N: 71.4\%, CompSt2: 72.7\%, $P=.9$ ). Midterm survival following the bPAB was not significantly different between groups (Figure 2).

\section{Assessment of and Interventions on the Pulmonary Arteries}

There were no significant differences in either LPA or RPA diameter on pre-Fontan angiography between the 2 groups. Hemodynamic assessment, including the ratio of pulmonary to systemic vascular resistance (Rp/Rs) and pulmonary vascular resistance measurements, prior to 


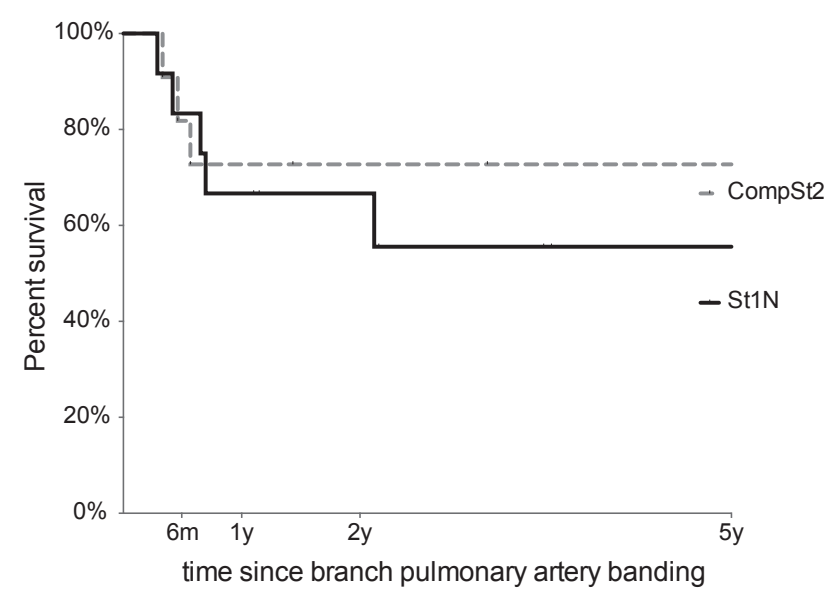

FIGURE 2. Long-term survival following bPAB stratified by subsequent palliation strategy, $P=.5$. CompSt2, Comprehensive stage 2; St $1 N$, stage 1 Norwood.

Stage 2 did not differ between groups. Complete obliteration of a lobar pulmonary artery (most commonly one of the upper lobe branches) occurred in $3(27.3 \%)$ CompSt2 patients and $2(14.3 \%)$ St $1 \mathrm{~N}$ patients $(P=.4)$. Operative interventions on the pulmonary artery occurred in $6(42.9 \%)$ St1N patients and $3(27.3 \%)$ CompSt2 patients $(P=.4)$. Similar proportions of patients required multiple interventions on the pulmonary artery (St1N: $21.4 \%$, CompSt2: $27.3 \%, P=.7)$. The number of interventions on the pulmonary arteries was poorly correlated with either surgical palliation strategy or the duration of PA bands as a continuous variable (Figure 3 ).

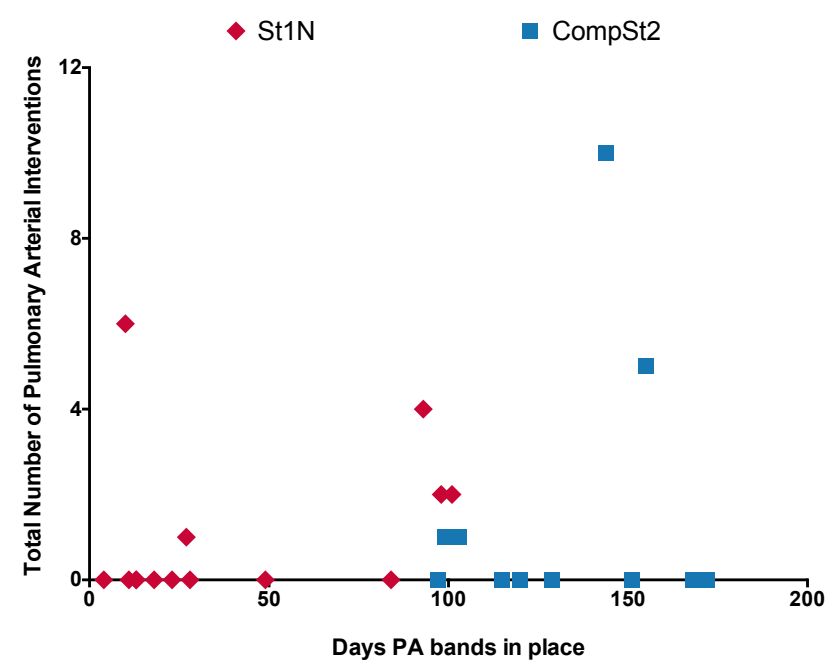

FIGURE 3. Scatter plot illustrating correlation between the duration the PA bands were in place and the total number of subsequent interventions on the pulmonary arteries. Correlation for $\mathrm{St} 1 \mathrm{~N}$ (red diamonds: $\mathrm{r}=0.28$, $P=.3$ ), for CompSt2 (blue squares: $\mathrm{r}=0.20, P=.6$ ). $P A$, Pulmonary artery; St $1 N$, stage 1 Norwood; CompSt2, comprehensive stage 2.

\section{Fontan Procedures}

Out of $8 \mathrm{St} 1 \mathrm{~N}$ patients surviving second-stage palliation, $6(75.0 \%)$ underwent Fontan palliation, $1(12.5 \%)$ died prior to Fontan as a result of sepsis, and $1(12.5 \%)$ was awaiting Fontan procedure. Among the $8 \mathrm{CompSt} 2$ patients surviving second-stage palliation, 6 underwent Fontan $(75.0 \%), 1(12.5 \%)$ underwent a 2 -ventricle repair, and 1 $(12.5 \%)$ died prior to Fontan palliation as the result of a traumatic brain injury. Overall, Fontan palliation was performed in $6(42.9 \%)$ St1N versus 7 (63.6\%) CompSt2 patients $(P=.3)$, at a median of 22.9 months (range $=16.9-26.8)$. Fontan hemodynamic assessment demonstrated a normal right-ventricle end-diastolic pressure in all patients; however, it was slightly higher in the CompSt2 group (7.6 \pm 1.3 vs $5.2 \pm 1.7, P=.03)$.

\section{Biventricular Repair and Orthotopic Heart Transplant}

There were 2 patients, 1 in each group (St1N: 1/14, 7.1\% vs CompSt2: 1/11, 9.1\%), who underwent biventricular repair following early single ventricle palliation. Two additional patients, 1 in each group, underwent orthotopic heart transplantation.

\section{DISCUSSION}

We have analyzed our outcomes of various palliation strategies following $\mathrm{bPAB}$ placement for single ventricle physiology with systemic outflow obstruction. We were unable to demonstrate a clear advantage to palliation through either an early St1N or a CompSt 2 strategy. Early and long-term mortality were similar between groups, and transplant-free survival through second-stage palliation was nearly identical. This is consistent with the limited previously published data. ${ }^{5,9,11,13}$

We did not identify any differences between patients who had simultaneous stenting of the arterial duct and those who had stenting delayed and were managed with PGE1. We feel that in patients with hemodynamic instability and preprocedural renal insufficiency, initial stabilization with bPAB followed by subsequent placement of a ductal stent may mitigate the risk of contrast-induced renal injury and improve long-term outcomes.

Some of the enthusiasm for the hybrid procedure stems from the idea that it provides a low-risk alternative palliation to allow patients to grow prior to undergoing definitive first and second stage palliation. ${ }^{5}$ Theoretically, waiting for definitive palliation might mitigate the risk associated with low birth weight, early gestational age, and aortic atresiaall factors known to increase mortality following an St1N procedure. ${ }^{1,4}$ In our experience, neither palliation strategy following $\mathrm{bPAB}$ entirely eliminated the risk associated with low birth weight. Although low-birth-weight St1N patients did not have a statistically significant association with 
mortality prior to stage 2 , this is most likely the result of limited sample size rather than a lack of effect. Despite the fact that we only included patients who survived to their subsequent palliation, the months of potential growth between $\mathrm{BPAB}$ and definitive palliation did not result in a lessening of the risk associated with low birth weight. This is consistent with broad results with surgery in low-birth-weight infants. ${ }^{15}$

Similar to findings from large studies of patients palliated with a shunt, ${ }^{16}$ the patients in both groups demonstrated poor somatic growth, with the mean change in weight-for-age percentile indicating that patients continued to lose ground following PAB placement until the SCPC. Poor growth is likely related to a combination of factors including underlying genetic syndromes, noncardiac congenital anomalies (especially of the gastrointestinal tract), as well as the ongoing volume load following bPAB and maintenance of ductal patency. ${ }^{16,17}$ This may explain the ongoing risk associated with low birth weight, because patients with low birth weights do not catch up with growth during the palliated period, demonstrating a mean increase of less than $4 \%$ in weight-for-age percentiles.

In fact, patients with poor outcomes (take-down of the SCPC) following CompSt2 procedure tended to have the procedure at an earlier age. This suggests that among patients who are not doing well with bPAB in place, delaying the second-stage palliation by performing an St1N procedure may be advantageous. Among the St1N patients, having bPAB in place for a longer duration was associated with higher mortality. This may be the direct result of bPAB duration, but is more likely related to the underlying reason for $\mathrm{bPAB}$ placement. Where the indication for bPAB is acute and self-limited (such as late diagnosis with hypotension and shock), controlling pulmonary blood flow will allow for resolution of the acute insult. These patents are the ones most likely to have a short bPAB duration. In contrast, where the underlying diagnosis is more complex, including prematurity, low birth weight, and genetic syndromes, there is no resolution of an acute process enabling early St1N and a short band duration. Furthermore, another subset of patients includes those initially planned for a CompSt 2 but who developed $\mathrm{AV}$ valve or ventricular dysfunction, or a recoarctation and were then directed to St1N. Whether these patients would have been advantaged by earlier St $1 \mathrm{~N}$ is not clear.

Aortic atresia was not a significant risk factor for mortality after St1N following bPAB. In contrast, it continued to be a risk factor following CompSt2. This may reflect the ongoing risk of ischemia and poor coronary perfusion resulting from retrograde arch flow throughout the period between $\mathrm{BPAB}$ placement and CompSt $2 .{ }^{18} \mathrm{In}$ contrast to other reports, ${ }^{19}$ we did not have a significant incidence of reverse coarctation, with only 1 patient having a velocity $>3 \mathrm{~m} / \mathrm{s}$ by Doppler echocardiography. However, even in the absence of clear reverse coarctation, the risk of ongoing myocardial ischemia, combined with the long cardioplegic arrest required during the CompSt 2 procedure, may place patients with aortic atresia at particularly high risk for poor outcomes with the CompSt2 palliation. ${ }^{11}$ These data would suggest that for patients with aortic atresia, delaying definitive palliation to CompSt2 is not an optimal strategy. Early St1N following hemodynamic stabilization may offer the best survival. It has been our practice in most cases to use a right ventricle-pulmonary artery shunt selectively in these patients in order to minimize the risk of myocardial ischemia in the interstage period, based in part on the improvement in survival seen in this subgroup in the Single Ventricle Reconstruction (SVR) Trial. ${ }^{4,20,21}$

Pulmonary arterial growth is critical to long-term candidacy for and successful palliation from Fontan procedure. We and others have shown that longer periods of bPAB are associated with poorer pulmonary arterial growth and an increased need for reintervention (both surgical and catheter-based) to optimize PA size. ${ }^{11,22,23}$ Although others have postulated that the need for PA interventions is related to technical aspects of the CompSt2, based on this data (as well as previously published data), ${ }^{22}$ we believe it is primarily related to the duration of PA banding required in order to bridge patients to a CompSt 2 procedure. Although duration of bPAB did not directly correlate with subsequent need for interventions, patients banded for longer than 90 days do have higher rates of subsequent intervention. ${ }^{22}$

It is notable that the 2 patients with nonsymmetric PAB sizes were the ones who had poorer outcomes following CompSt2. Our general practice is to band the branch PAs to the same size. The use of differential sizes suggests that there was difficulty in accurately titrating pulmonary blood flow. Although larger children and those without significant preexisting pulmonary vascular disease may tolerate some degree of pulmonary overcirculation in the early post-band period, patients with low birth weights, bronchopulmonary dysplasia, elevated pulmonary vascular resistance, and a restrictive atrial septum, more accurate control of pulmonary blood flow may be required. This may also be part of the explanation for the poor outcomes associated with low birth weight in both groups. Patients of low birth weight have smaller nominal branch PA sizes; thus, banding to 2 or $2.5 \mathrm{~mm}$ results in substantially different pulmonary blood flow. In any case, the poor outcomes associated with differentially sized PABs following CompSt2 suggests that in patients where either small size or pulmonary vascular resistance makes titration difficult, an early St $1 \mathrm{~N}$ may be more advisable. Whether there are subgroups in whom the CompSt2 procedure would be optimal is less clear, and these data do not elucidate this issue further. Given the risk associated with longer duration of pulmonary artery banding, the potential for ongoing 
myocardial ischemia-especially in patients with aortic atresia, and the high-risk nature of the CompSt2 procedure itself (both here and as reported by others), ${ }^{5,11,22,24}$ we prefer an early St1N following initial bPAB placement in most cases.

There was no significant difference in the ultimate success of Fontan palliation, but throughout the data analysis there were trends toward improved overall survival and improved survival to Fontan palliation among patients in the CompSt 2 group. However, by definition, patients in the CompSt2 group had to survive long enough to get to their palliative procedure, so one would expect the survival to be higher in those patients. Furthermore, it was often the patients not doing well following bPAB placementdemonstrating atrioventricular valve regurgitation, ventricular dysfunction, or a recurrent coarctation-who were directed toward an early St1N. Thus, there is a selection bias inherent in the comparison. A complete assessment of the 2 strategies would necessitate randomizing patients to one strategy or the other and then following those patients from $\mathrm{bPAB}$ placement.

\section{Limitations}

These data are based on a single-institutional experience with bPAB placement for systemic outflow obstruction. As such, there is a limited sample size, and it is likely that additional factors not significant in our analysis may have clinical relevance. Furthermore, patients were not randomized to either strategy; rather, the strategy was selected largely according to the clinical course of patients before and after banding, significantly biasing our analysis. Finally, as noted above, a comprehensive analysis of the CompSt 2 procedure would necessitate accounting for patients who, despite being intended for a CompSt 2 procedure, did not survive to that procedure. This was not possible within the constraints of a retrospective study.

\section{CONCLUSIONS}

In summary, we have shown that both palliation strategies are viable options following bPAB placement. However, certain subgroups may benefit from an early St1N, including patients with aortic atresia and those with early failure to thrive following bPAB placement. Given the potential risks associated with longer duration of bPAB-especially regarding PA growth-it is not clear which patients are likely to benefit from CompSt2 over St1N. Larger patient populations, perhaps as part of multicenter cohort studies, are necessary in order to fully assess the relative merits of each palliation strategy.

\section{References}

1. Tabbutt S, Dominguez TE, Ravishankar C, Marino BS, Gruber PJ, Wernovsky G, et al. Outcomes after the stage I reconstruction comparing the right ventricular to pulmonary artery conduit with the modified Blalock Taussig shunt. Ann Thorac Surg. 2005;80:1582-90; discussion 1590-1.

2. Tweddell JS, Hoffman GM, Mussatto KA, Fedderly RT, Berger S, Jaquiss RD, et al. Improved survival of patients undergoing palliation of hypoplastic left heart syndrome: lessons learned from 115 consecutive patients. Circulation. 2002; 106(12 Suppl 1):I82-9.

3. Ohye RG, Sleeper LA, Mahony L, Newburger JW, Pearson GD, Lu M, et al. Comparison of shunt types in the Norwood procedure for single-ventricle lesions. N Engl J Med. 2010;362:1980-92.

4. Tweddell JS, Sleeper LA, Ohye RG, Williams IA, Mahony L, Pizarro C, et al. Intermediate-term mortality and cardiac transplantation in infants with singleventricle lesions: risk factors and their interaction with shunt type. $J$ Thorac Cardiovasc Surg. 2012;144:152-9.

5. Galantowicz M, Cheatham JP, Phillips A, Cua CL, Hoffman TM, Hill SL, Rodeman R. Hybrid approach for hypoplastic left heart syndrome: intermediate results after the learning curve. Ann Thorac Surg. 2008;85:2063-70; discussion 2070-1.

6. Bacha EA, Daves S, Hardin J, Abdulla R-I, Anderson J, Kahana M, et al. Singleventricle palliation for high-risk neonates: the emergence of an alternative hybrid stage I strategy. J Thorac Cardiovasc Surg. 2006;131:163-71.e2.

7. Ota N, Murata M, Tosaka Y, Ide Y, Tachi M, Ito H, et al. Is routine rapid-staged bilateral pulmonary artery banding before stage 1 Norwood a viable strategy? J Thorac Cardiovasc Surg. 2014;148:1519-25.

8. Russell RA, Ghanayem NS, Mitchell ME, Woods RK, Tweddell JS. Bilateral pulmonary artery banding as rescue intervention in high-risk neonates. Ann Thorac Surg. 2013;96:885-90.

9. Guleserian KJ, Barker GM, Sharma MS, Macaluso J, Huang R, Nugent AW, Forbess JM. Bilateral pulmonary artery banding for resuscitation in high-risk, single-ventricle neonates and infants: a single-center experience. J Thorac Cardiovasc Surg. 2013;145:206-13; discussion 213-4.

10. Pizarro C, Derby CD, Baffa JM, Murdison KA, Radtke WA. Improving the outcome of high-risk neonates with hypoplastic left heart syndrome: hybrid procedure or conventional surgical palliation? Eur J Cardiothorac Surg. 2008; 33:613-8.

11. Baba K, Kotani Y, Chetan D, Chaturvedi RR, Lee K-J, Benson LN, et al. Hybrid versus Norwood strategies for single-ventricle palliation. Circulation. 2012; 126(11 Suppl 1):S123-31.

12. Pizarro C, Norwood WI. Pulmonary artery banding before Norwood procedure. Ann Thorac Surg. 2003;75:1008-10.

13. Gomide M, Furci B, Mimic B, Brown KL, Hsia T-Y, Yates R, et al. Rapid 2-stage Norwood I for high-risk hypoplastic left heart syndrome and variants. $J$ Thorac Cardiovasc Surg. 2013;146:1146-51; discussion 1151-2.

14. Pizarro C, Murdison KA. Off pump palliation for hypoplastic left heart syndrome: surgical approach. Semin Thorac Cardiovasc Surg Pediatr Card Surg Ann. 2005;66-71.

15. Hickey EJ, Nosikova Y, Zhang H, Caldarone CA, Redington A, Van Arsdell GS. Very low-birth-weight infants with congenital cardiac lesions: is there merit in delaying intervention to permit growth and maturation? J Thorac Cardiovasc Surg. 2012;143:126-36. 136.e1.

16. Ravishankar C, Zak V, Williams IA, Bellinger DC, Gaynor JW, Ghanayem NS, et al. Association of impaired linear growth and worse neurodevelopmental outcome in infants with single ventricle physiology: a report from the pediatric heart network infant single ventricle trial. J Pediatr. 2013;162: 250-6.e2.

17. Williams RV, Zak V, Ravishankar C, Altmann K, Anderson J, Atz AM, et al. Factors affecting growth in infants with single ventricle physiology: a report from the Pediatric Heart Network Infant Single Ventricle Trial. J Pediatr. 2011;159: 1017-22.e2.

18. Hsia T-Y, Cosentino D, Corsini C, Pennati G, Dubini G, Migliavacca F. Modeling of Congenital Hearts Alliance (MOCHA) Investigators. Use of mathematical modeling to compare and predict hemodynamic effects between hybrid and surgical Norwood palliations for hypoplastic left heart syndrome. Circulation. 2011; 124(11 Suppl):S204-10.

19. Baba K, Honjo O, Chaturvedi R, Lee KJ, Van Arsdell G, Caldarone CA, et al. "Reverse Blalock-Taussig shunt": application in single ventricle hybrid palliation. J Thorac Cardiovasc Surg. 2013;146:352-7.

20. Pizarro C, Norwood WI. Right ventricle to pulmonary artery conduit has a favorable impact on postoperative physiology after Stage I Norwood: preliminary results. Eur J Cardiothorac Surg. 2003;23:991-5.

21. Bradley SM, Simsic JM, McQuinn TC, Habib DM, Shirali GS, Atz AM. Hemodynamic status after the Norwood procedure: a comparison of right 
ventricle-to-pulmonary artery connection versus modified Blalock-Taussig shunt. Ann Thorac Surg. 2004;78:933-41; discussion 933-41.

22. Davies RR, Radtke WA, Klenk D, Pizarro C. Bilateral pulmonary arterial banding results in an increased need for subsequent pulmonary artery interventions. J Thorac Cardiovasc Surg. 2014;147:706-12.

23. Dave H, Rosser B, Knirsch W, Hubler M, Prêtre R, Kretschmar O. Hybrid approach for hypoplastic left heart syndrome and its variants: the fate of the pulmonary arteries. Eur J Cardiothorac Surg. 2014;46:14-9.

24. Pizarro C, Derby CD, Radtke WA. Hybrid procedure for hypoplastic left heart syndrome: the Nemours approach. Oper Techn Thorac Cardiovasc Surg. 2009; 14:86-98.

\section{Discussion}

Dr Pirooz Eghtesady (St Louis, Mo). Ryan, great job! Nice presentation and succinctly done. For the sake of time, I am going to skip to the questions with the goal of trying to get to a better understanding of the data. This is an important topic and very timely. I am going to emphasize really that one figure that you have with patients going different pathways, and maybe you can just bring that slide up please.

So there were 3 patients who just had their pulmonary artery (PA) banded and maintained on prostaglandins, in the right-hand side of your figure, who died in the process. What was the cause of death or mechanism of death in these 3 kids?

Dr Davies. The group of patients who had a PA band and died without further intervention (as well as the 8 children who had a stent and died before subsequent palliation) formed a heterogeneous group. They included children who presented in severely moribund states who had bands placed for an attempt at initial stabilization but did not recover enough to undergo another operation, as well as at least 2 children who had Ellis-van Creveld or other severe syndromic defects and were banded to enable discharge to home with their family. Overall, this group of children presented extremely ill, with complicated syndromic problems, and ultimately never stabilized to the point where a subsequent surgical palliation was an option.

Dr Eghtesady. And then there are the 16 patients in the middle of your figure there who underwent ductal stenting subsequent to PA banding. So my question, kind of multiparts to it, is that, first, how was that done? Was that done in the operating room, by reopening the chest, or in the cath lab, done percutaneously? Second, when was it done, on average, relative to the PA banding? And, third, why was that approach taken for these patients? Lastly, at the end of the day, for these particular 16 patients, how did they fare? How many of them died or ended up requiring transplant?

Dr Davies. Patients who had ductal stenting following (rather than simultaneous to) pulmonary artery banding had the ductal stent placed as part of an open-chest hybrid procedure. This was usually performed following the placement of bands to achieve hemodynamic stability (eg, most commonly, the bands may have been placed in the intensive care unit in a patient who was moribund in shock). In these patients (some of whom already had renal failure), the use of prostaglandin E was felt to be better than placing them through a ductal stenting procedure, especially with the risk of renal failure from the dye load. The timing of ductal stenting was usually determined by resolution of renal failure, decreased creatinine, and improvement in hemodynamics.

In terms of their long-term outcomes, we did not analyze those separately from patients who had a ductal stent placed at the same time. It is an important question and one that we should examine in further analysis. We did evaluate whether the outcomes following a stage 1 Norwood were altered by the presence of a ductal stent (compared with those maintained on prostaglandin E), and that did not seem to make a difference in terms of the outcomes.

Dr Eghtesady. Well, that was actually my next question. Those 8 patients who initially had a plan to go down to comprehensive Stage 2, and then obviously they got diverted to going down a Norwood Stage 1, what happened? How did these patients do in general and why did the decision tree change?

Dr Davies. These patients would fall into a couple of categories. One of the more common situations is simply cardiologist and team preference. Patients may have had a ductal stent placed but then were doing well with improved hemodynamics, and the decision was made to move them back to the standard palliation pathway by performing an early stage 1 Norwood rather than an eventual comprehensive stage 2 . So that may represent something of an institutional bias where we have more patients on the traditional Stage 1 pathway than going through a comprehensive Stage 2 pathway.

Another group would be those in whom the challenges present before the ductal stenting, for example atrioventricular (AV) valve regurgitation, resolved sooner than anticipated. For example, a patient with $\mathrm{AV}$ valve regurgitation that was not expected to resolve had improvement in AV valve function over the period of 2 to 3 weeks with improvement in ventricular function and so was directed toward a Stage 1 rather than waiting longer for the comprehensive Stage 2.

Dr Eghtesady. So really that brings me to my final question. I am going to sort of put you on the spot. So one of the beauties of things like this when you go back and look at your results, you kind of learn some lessons, some pearls. So based on what you have seen and what you have learned, which patients would you push down the pathway of PA banding and prostaglandins and then do the Stage 1 Norwood, the so-called rapid 2-stage or whatever you want to call it, and then who would you push straight toward the comprehensive Stage 2?

Dr Davies. My bias, based on this study and some of the other data we have presented previously, would be to lean toward the rapid 2-stage Norwood procedure for most patients. My reasoning for this is that the patients who do well in either group are those with rapidly treatable problems. They present in shock or renal failure, or they have necrotizing enterocolitis, we then place pulmonary artery bands, resulting in improved systemic cardiac output, and the patient stabilizes. After examining these data, it appears that the outcomes are equivalent between groups and so there is not much reason to wait beyond that initial period of stabilization. By placing a ductal stent, leaving the bands in place for months and later performing a more complex comprehensive Stage 2 procedure, we add the potential for additional complications without any clear benefit. 
There may be specific groups who would benefit from waiting for a comprehensive Stage 2. However, I think our data does not clearly delineate a group that will do better with the comprehensive Stage 2 procedure.

Dr Joseph J. Amato (Chicago, Ill). Just a minor point on pulmonary artery banding. Did you secure the bands? Were there any band migrations? Did you have any problem with banding?

Dr Davies. We usually do secure the bands with a Prolene suture. We have not had significant problems with band migrations. However, our data from other studies suggest that even in the absence of band migrations there is a higher risk for pulmonary interventions among patients with branch pulmonary artery bands when compared to traditional Stage 1 Norwood procedures without banding. Given these results, it may be important to move the bands more proximally on the PAs if at all possible.

Dr Charles D. Fraser (Houston, Tex). Ryan, congratulations on the hard work. This is clearly a sick group of patients, and I am sure you realize and will comment on this in the manuscript that the fact that you have not demonstrated difference could be related to the numbers of patients.

The question is, for example, those 3 children that got banded, kept on prostaglandin and sent home. Whom do you not offer surgery to, or does everybody get an operation irrespective of presentation, size, comorbidities, right ventricular function, et cetera? Does everybody get an operation?

Dr Davies. Our bias is to offer everyone an operation, recognizing that some of them will not have good outcomes. It is clearly a very sick population, and it does not even include those patients who died before they had one of those palliative strategies, and obviously the mortality rate is high. If you look at other series of rapid Stage 1 Norwoods (the series from Great Ormond Street, the series from Texas, and the Japanese series among others) each group is slightly different and this makes the actual outcomes difficult to compare. However, if you look at the ones that have the sickest patients, they have an extremely high mortality rate, which is consistent with the high mortality rate we have in this series; ultimately, the outcomes depend significantly on patient selection. If one offers something to everyone (as we generally do), your mortality rates are going to be high.

The advantage of the hybrid in these cases is that branch PA banding can stabilize patients with a relatively small operation. It then becomes clear whether control of pulmonary blood flow results in significant improvement (in renal function, respiratory function, etc) and puts the child into a position where he or she can tolerate a bigger procedure. It is much more challenging to take those extremely ill patients and putting them straight into a Norwood procedure in marginal clinical condition.

Dr Fraser. I am sure these data will help you counsel families in the prenatal period.

Dr Davies. I think it does give you a better sense for the impact of unstable hemodynamics, significant comorbidities, and genetic syndromes has on the early outcomes, regardless of approach.
Dr Christopher A. Caldarone (Toronto, Ontario, Canada). If I can add a comment and a question, the only rationale for utilizing a strategy whereby a bilateral pulmonary artery banding ductal stented state is followed by a Norwood and then a Stage 2 procedure is if the ability to do the Norwood after a bilateral pulmonary artery banding is somehow easier and safer than a "de novo" Norwood. This might be true if the hemodynamics were stabilized with the hybrid and the subsequent Norwood was not made more difficult, perhaps because you did not put the ductal stent in. If the increased hemodynamic stability and surgical ease is great, then your argument that this might be a good strategy is supported.

Another issue that might support your strategy is if the mortality rate at the comprehensive Stage 2 is very high. In contrast, if the mortality rate at the comprehensive Stage 2 goes to zero, then there is not much to support your argument.

So among the patients who died after the comprehensive Stage 2 , can you defeat this clinical problem and thereby eliminate the need for this alternative strategy?

Dr Davies. This is an excellent point. We have certainly found that the comprehensive stage 2 procedure remains technically challenging. The mortalities present following that procedure were technical issues in that there were 2 patients who had to have their Stage 2 taken down immediately due to superior vena cava syndrome. Even in retrospect, it has been difficult to identify any diagnostic test that identified the challenges presented by the superior cavopulmonary connection in these patients.

In contrast, the mortalities in Stage 1 procedures tended to be the result of underlying patient factors-syndromic factors, liver failure, etc-and not necessarily technical issues. That is partly is why we have a bias to direct patients toward Stage 1s, because our technical outcomes (even with the stent having been put in place) are perhaps slightly better. Especially if the ductal stent has only been in for 1 or 2 weeks, we find it is relatively easy to remove it in contrast to when it had been there 3 months.

Attempting to lower the mortality rate for Stage 2 has been challenging. As noted above, it is not clear, even in retrospect, what it is that was missed that would have told us that the patient was not going to tolerate a superior cavopulmonary connection. Furthermore, I do not know that anyone has really lowered the mortality from that operation to a point where it can really clearly be said to be preferred.

The other important aspect to mention here (and this is based both on this data and previous publications), but there is an impact of waiting for the comprehensive Stage 2 with bands and a ductal stent in place. We have shown previously, as has your group in Toronto, that there is a negative impact on pulmonary arterial growth and the need for reintervention that is related to having bands in place on the pulmonary arteries. Furthermore, there are issues with retrograde arch obstruction and the potential for needing a reverse BT [Blalock-Taussig] shunt. Thus, even with lowering the mortality of the actual stage 2 procedure, it is not clear that the overall survival and anatomic and physiologic outcomes through that stage are necessarily equivalent. 
Dr Caldarone. Well, we are relentlessly optimistic. I would say if your comprehensive Stage 2 mortality is due to technical factors, you will be able to conquer them.

Dr Thomas L. Spray (Philadelphia, Pa). I am a little confused, but was there an attempt to randomize treatment. Because if so, there was a very high crossover rate. And if that is the case, then comparing these variables in terms of anatomy and other things really is not going to tell us much of anything.

Dr Davies. This is an important point and clearly one of the limitations of this study. There was no randomization, and we did not have any record of the "intent to treat" at the initial palliation decision.

Dr Spray. If that is the case, how did you pick the ones that you went ahead and did a Norwood on versus the ones that went to a comprehensive Stage 2? Was it because they were not doing as well? They were doing great and you thought let us just go ahead and do it? I mean why would you go ahead and do a Norwood if they were doing well on a pathway to a comprehensive Stage 2? I do not quite understand that.

Dr Davies. There are broadly 2 groups of patients who underwent ductal stenting and then subsequent stage 1 Norwood procedure rather than continuing along the Stage palliation pathway. The first are patients who had resolution of a risk factor and in whom there was a decision to convert the patient back to our usual palliation pathway. The second were patients with imperfections in their palliation: ductal stent obstruction, recoarctation, elevated pulmonary blood flow, and worsening AV valve regurgitation. Often, in these patients, our preference has been to move ahead with a stage 1 Norwood rather than multiple reinterventions to try to perfect the hybrid palliation. If Christian wants to answer in more detail- he has been the primary surgeon on most of these cases.

Dr Christian Pizarro (Wilmington, Del). Yes, I think Ryan arrived when the train already left the station on this one. There are a couple of things that are important. One is the fact that there is a lot of cardiology influence about what to do with a specific patient. I think that for reasons that Chris alluded to earlier, they are not entirely convinced that the impact of bands of the branch pulmonary arteries effect is negative, and therefore when there is a clear-cut indication, like contraindication for anticoagulation, once we are beyond that and the contraindication is no longer present, the question is why do not we just go ahead and do a Norwood.

The other end of the spectrum is the patient who got a restriction at the level of the atrial septum or other issues, which resulted in a challenging physiology. In some of these, we thought an initial hybrid approach would be advantageous and allow the patient's condition to improve before proceeding with a Norwood. A considerable number of these patients had aortic atresia, and now we have mounting evidence to suggest that those patients in particular are probably better served with the Norwood rather than waiting in the long run.

So unfortunately, it is not randomized and it is highly imperfect, but I think that the lessons we distilled include the fact that if there is a clear reversible target, a hybrid procedure can provide appropriate palliation until it gets resolved, then the risk of a Norwood procedure is not increased. In cases when the indication for a hybrid palliation is due to a chronic medical issue, which is not resolved, then mortality remains elevated perhaps not initially but at some point along the palliative sequence. That is what we have learned from it.

Dr Caldarone. If that is the case, just could I ask, what was the mean age of the patients in the Norwood strategy and the mean age in the comprehensive Stage 2 strategy?

Dr Davies. The mean age for the comprehensive Stage 2 was 4.5 months. In the Stage 1 Norwood group, it was a mean of 6 weeks, but a median of 4 weeks.

Dr Pizarro. It is definitely less than 6 weeks. It is probably at a median of about 4 .

Dr Davies. As has been noted, the primary limitation of this study is the lack of randomization and the lack of a priori determination of palliation strategy. If patients had been assigned to one strategy or the other at the placement of PA bands, then there would be a sense of what the original intent was in assigning patients to each group. On the other hand, that data are simply not available, and this represents one of the few series that includes patients managed with a range of strategies following branch PA bands, so it is still valuable to examine our outcomes even with these limitations. 